\title{
About the effectiveness of counter blasting with chamber mining system
}

\author{
Igor Sokolov ${ }^{1 *}$, Yuri Antipin ${ }^{1}$, Kirill Baranovsky ${ }^{1}$ and Artem Rozhkov ${ }^{1}$ \\ ${ }^{1}$ Institute of Mining of the Ural branch of the Russian Academy of Sciences, Laboratory of \\ Underground Geotechnology, 620075, Ekaterinburg, Russia
}

\begin{abstract}
When underground mining of Ural copper deposits with a chamber mining system, an urgent scientific and practical task is to increase the productivity of loading- delivery machines for the ore drawing from secondary chambers. The technogenic disturbance of the massif of such chambers in combination with the non-alternative use of a blasthole ring scheme of breaking leads to an increased output of oversized fractions. With an increase of oversized ore output, operating costs for the drawing and delivery of ore increase, tire wear, fuel and lubricants consumption increases. In this article, the possibility of reducing the oversize ore output in secondary chambers by using counter blasting of the breaking layers is considered. As a result of the research, the parameters of effective counter blasting with blasthole ring charges were established, namely, the distance between the working faces in the chamber, the angle of ore pieces meeting and the line of least resistance.
\end{abstract}

Keywords: Copper ore, counter blasting, oversized ore, blasthole ring charges, line of least resistance

\section{Introduction}

Mining of thick ore bodies of copper deposits in the Urals (Gayskoye, Sibayskoye, Oktyabrskoye, Uzelginskoye, etc.) is mainly carried out with chamber mining systems with solidifying filling and the use of self-propelled equipment for ore drawing and delivery [1]. The ore massif in the chambers of the II and III stages was disturbed by blasting operations during the breaking of ore in the chambers of the first stage. Therefore, in the ore pillars under the influence of rock pressure, blastholes are often disturbed and lost. Under these conditions, there is an increased yield of oversized ore (1.3-2.5 times higher than in the chambers of the first stage) during ore breaking [2] and, as a result, a significant decrease in the productivity of load-haul-dumpers (LHD) [3] in drawing and delivery of ore from the chamber. Also, in work [4] it is noted that the value of the oversized ore yield for copper deposits increases 1.3-1.5 times for every 300-400 m increase in the depth of mining.

For mining of the Gayskoye deposit, a chamber- filling system is used with chamber parameters $-80 \mathrm{~m}$ high, 30-50 m long and $20 \mathrm{~m}$ wide, providing for two drilling sublevel horizons $26-27 \mathrm{~m}$ high. At the first stage of the mining, chamber reserves were breaking by parallel blastholes with diameter $105 \mathrm{~mm}$. The central parts of the ore bodies are

\footnotetext{
* Corresponding author: geotech@igduran.ru
} 
represented by massive and very stable ores, sufficiently strong and practically not fractured. Many parts of the ore bodies are broken by cracks filled with chlorite-sericite shales, which are prone to swelling upon contact with water, as a result of which, already drilled blastholes often turned out to be blocked [5].

When drilling the chamber with parallel blastholes, it was necessary to pass a large volume of closely spaced drilling working along the strike of the ore body, which led to a decrease in their stability and safety of drilling and blasting operations. Therefore, a transition was made to blasthole ring schemes, which provide for drilling blastholes from workings located across the strike of the ore body. With a blasthole ring schemes, the average yield of oversized ore in the secondary chambers increased by $19 \%$ [1].

The analysis of the cost of ore mining showed that the cost of ore breaking is $12.5 \%$, and for ore drawing and delivery (including secondary crushing) $-18.1 \%$ of the total costs. The most effective way to increase the efficiency of ore drawing and delivery is to improve the quality of crushing, which is an urgent scientific and technical task.

\section{Materials and Methods}

A promising direction for improving the quality of ore crushing in secondary chambers with a level-chamber system with a filling is the use of counter blasting of blasthole rings, in which additional crushing of colliding pieces of ore occurs [6].

The critical flight speed of ore pieces $\left(\mathrm{V}_{\text {cr }}\right)$, at which they are crushed, can be determined by the formula [7] (Fig. 1)

$$
V_{\text {cr }}=\frac{4,45 \sigma_{\mathrm{cs}}}{\sin \frac{\alpha}{2}} \sqrt{\frac{g}{\gamma E}}, \mathrm{~m} / \mathrm{s}
$$

where $\sigma_{\mathrm{sc}}-$ ultimate compressive strength of the ore, MPa; $\alpha$ - angle of meeting of ore pieces, degrees; $\mathrm{E}$ - modulus of elasticity, N/m² $\mathrm{g}$ - acceleration of gravity, $\mathrm{m} / \mathrm{s}^{2} ; \gamma$ - ore density, $\mathrm{kg} / \mathrm{m}^{3}$.

Accordingly, for the destruction of pieces, their initial speed $\left(\mathrm{V}_{\mathrm{i}}\right)$ must be greater than or equal to $\mathrm{V}_{\mathrm{cr}}$, and can be calculated by the formula [8] (Fig. 2).

$$
\begin{aligned}
& V_{\mathrm{i}}=\frac{72000 C_{\mathrm{eq}}}{\gamma W^{3}}, \mathrm{~m} / \mathrm{sec} \\
& C_{\mathrm{eq}}=1,3 \frac{W^{0,375}}{\gamma^{0,125}} C_{\mathrm{ex}}^{1,125}, \mathrm{~kg}
\end{aligned}
$$

where $\mathrm{C}_{\mathrm{eq}}$ - equivalent concentrated explosive charge, $\mathrm{kg}$; $\mathrm{W}-\mathrm{LLR}, \mathrm{m} ; \mathrm{C}_{\mathrm{ex}}$ - the weight of the elongated charge per $1 \mathrm{~m}$ of the blasthole, $\mathrm{kg}$. 


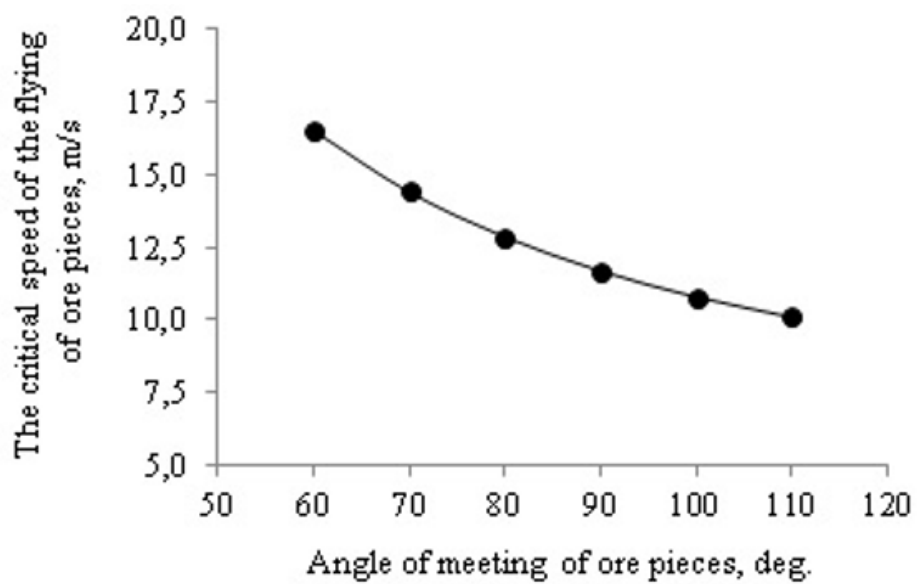

Fig. 1. Dependence of the critical flight speed of ore pieces on the angle of their meeting

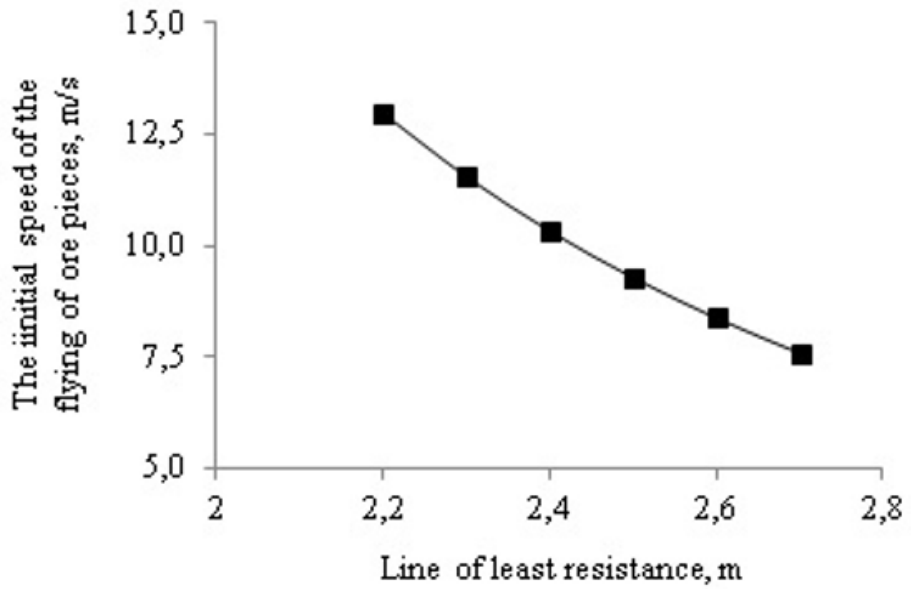

Fig. 2. Dependence of the initial flight speed of ore pieces from LLR

The angle of meeting of pieces of ore largely depends on the flight range of the pieces $\left(l_{\mathrm{fr}}\right)$, which can be determined by the formula (Fig. 3 )

$$
l_{\mathrm{fr}}=V_{\mathrm{i}} \sqrt{\frac{H_{\mathrm{ch}}}{g}}, \mathrm{~m}
$$

where $\mathrm{H}_{\mathrm{ch}}$ - the height of the chamber, $\mathrm{m}$.

Further, it is necessary to establish at what value of the LLR the angle of meeting of ore pieces is provided, at which the initial speed of the pieces is greater than or equal to the critical one. For this, we propose to use the following formula (Fig. 4)

$$
\alpha=\arctan \frac{l_{\mathrm{fr}}}{0,5 H_{\mathrm{ch}}}, \operatorname{deg} .
$$




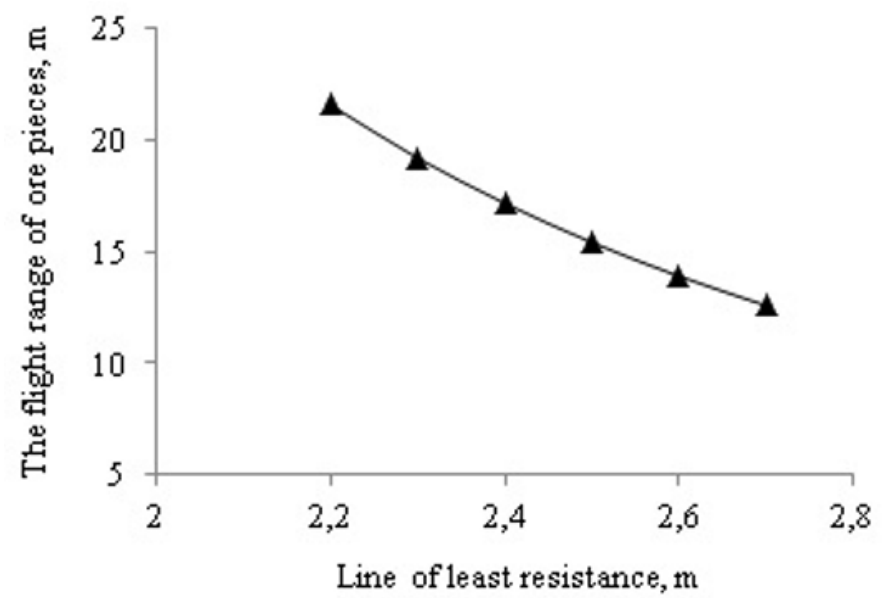

Fig. 3. Dependence of the flight range of ore pieces from LLR

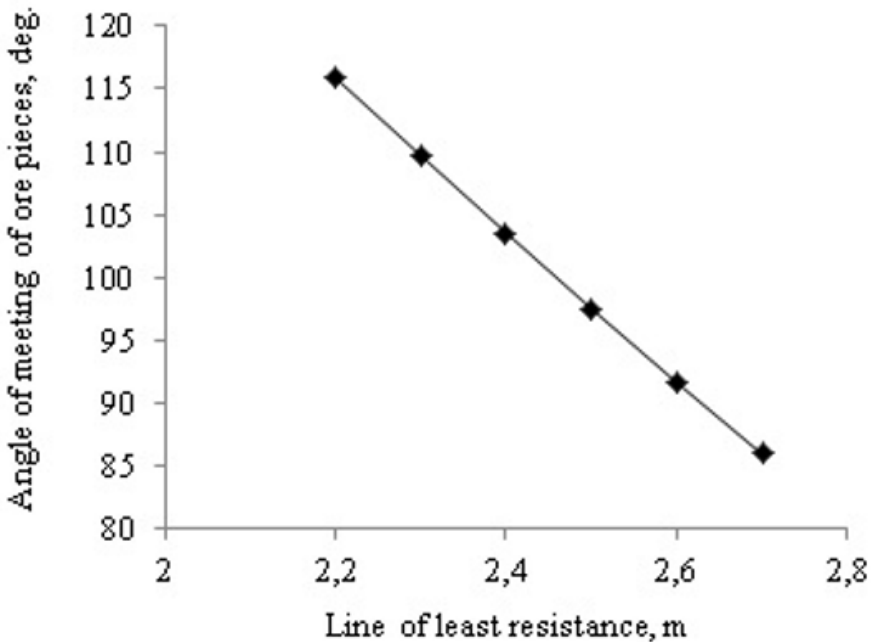

Fig. 4. Dependence of the angle of meeting of ore pieces from the LLR

The analysis of the obtained dependences showed that the condition under which the initial speed of the pieces is greater than or equal to the critical one is fulfilled when the LLR is less than or $2.5 \mathrm{~m}$ wound (for blastholes with a diameter of $105-110 \mathrm{~mm}$ ). For reasons of reducing the specific volume of drilling for practical use, it is recommended that LLR $2.5 \mathrm{~m}$. Taking into account the non-straightness of the flight path of ore pieces [9], with this LLR, the required angle of their meeting (98-110 ${ }^{\circ}$ ) is provided. It is important that at the same time a sufficient contact area of the opposing blasted layers is provided. Obviously, with the parameters of the span between the faces in the chamber, exceeding the calculated flight range of the ore pieces, the contact area will begin to decrease significantly with the breaking of each subsequent layers. Based on these considerations, it was found that the counter blasting method in the conditions under consideration (LLR $-2.5 \mathrm{~m}$ ) is effective when the distance between the working faces is not more than $15 \mathrm{~m}$.

Further breaking in the chambers upon reaching the distance between the opposite faces of $15 \mathrm{~m}$ is rational to perform with diagonal blasthole rings located in different planes and forming a wedge-shaped face with an angle between planes $90-100^{\circ}$ (Fig. 5). 


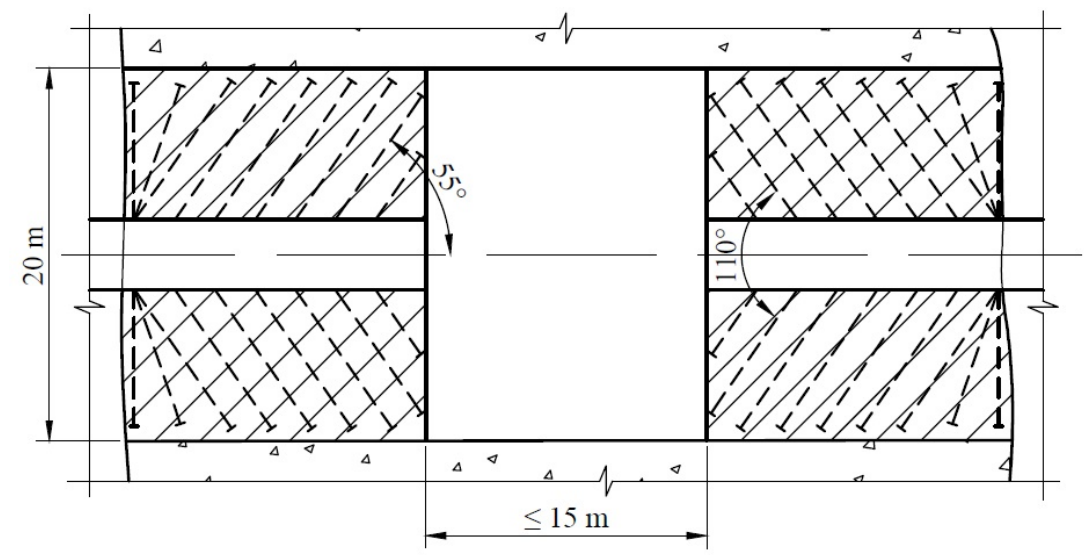

Fig. 5. Scheme of ore breaking in the chamber by diagonal blasthole rings

The scheme of ore breaking with a diagonal blasthole rings and counter blasting allows additional crushing of ore pieces when they collide, regardless of the length of the treatment chambers.

\section{Results and Discussion}

For industrial tests, a scheme was adopted for breaking ore in secondary chambers with counter and then diagonal blasthole rings with a wedge-shaped face with an angle of 90$100^{\circ}$. The yield of oversized material was assessed by two methods: direct measurement of oversized pieces of ore and by the consumption of explosives for secondary crushing. The results of industrial tests and timing observations are shown in Table 1.

Table 1. Results of industrial tests of ore breaking schemes in secondary chambers

\begin{tabular}{|l|c|c|}
\hline \multicolumn{1}{|c|}{ Name of indicators } & $\begin{array}{c}\text { Counter and diagonal } \\
\text { blasthole rings }\end{array}$ & $\begin{array}{c}\text { The average data of } \\
\text { the mine }\end{array}$ \\
\hline Blasthole grid $(\mathrm{W} \times \mathrm{a}), \mathrm{m}$ & $2.5 \times 2.5$ & $2.5 \times 2.5$ \\
\hline Ore yield from $1 \mathrm{~m}$ of the blasthole, $\mathrm{m}^{3} / \mathrm{m}$ & 3.6 & 3.8 \\
\hline $\begin{array}{l}\text { Specific consumption of explosives for } \\
\text { primary breaking, } \mathrm{kg} / \mathrm{m}^{3}\end{array}$ & 1.83 & 0.52 \\
\hline $\begin{array}{l}\text { Specific consumption of explosives for } \\
\text { secondary crushing, } \mathrm{kg} / \mathrm{m}^{3}\end{array}$ & 0.089 & 2.12 \\
\hline $\begin{array}{l}\text { Total specific consumption of explosives, } \\
\mathrm{kg} / \mathrm{m}^{3}\end{array}$ & 1.92 & 19.3 \\
\hline Yield of oversized ore, $\%$ & 4.9 & 380 (delivery length \\
$180 \mathrm{~m})$
\end{tabular}

According to the results of chronometric observations [5], the effect of the yield of oversized ore $(\eta)$ on the duration of loading a dump truck $\left(\mathrm{t}_{\mathrm{load}}\right)$ with a delivery length of $80 \mathrm{~m}$ was established (Fig. 6)

$$
t_{\text {load }}=2,80+0,51 \eta-1,25 \ln \eta, \min .
$$




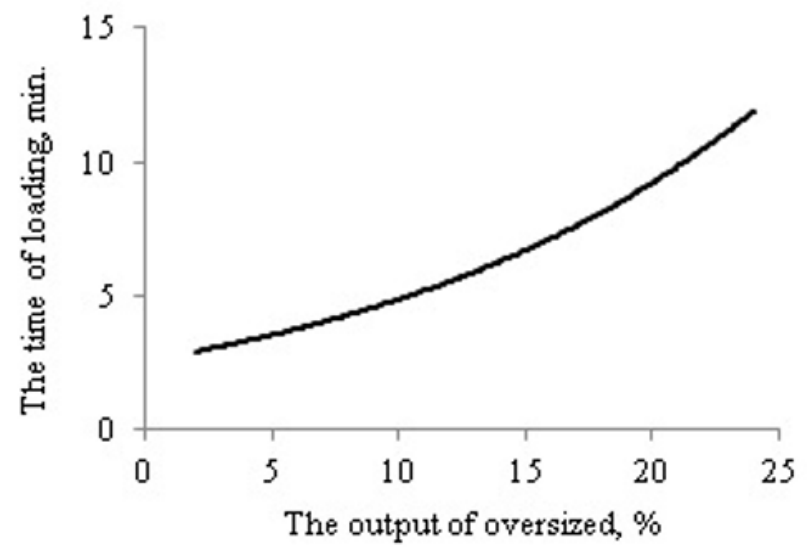

Fig. 6. Influence of the yield of oversized ore on the loading time of the dump truck

From the obtained graph it can be seen that with the proposed option, the productivity of the LHD at the ore drawing increases by about 1.5-2.0 times with a decrease in the yield of oversized ore from 19 to $5 \%$. With an increase in the delivery length to $150-200 \mathrm{~m}$, it is possible to predict an increase in the productivity of the LHD on average up to 1.2-1.5 times.

The results obtained show that the proposed version of ore breaking in secondary chambers is more efficient than the standard scheme in almost all indicators and allows to significantly increase the productivity of self-propelled loading and delivery equipment.

\section{Conclusion}

In the conditions of increasing the depth of underground mining of the Ural copper deposits and increasing the production capacity of mining enterprises, improving the schemes and parameters of ore explosive breaking is one of the determining factors for improving the efficiency of underground geotechnology. Research of parameters of blasting ore with level-chamber mining system with filling in the conditions of Gaisky underground mine show that the proposed method and established effective parameters of counter blasting blasthole ring charges (the distance between the working faces in the chamber, the angle of ore pieces meeting and the line of least resistance) compared with the baseline increase of the productivity of LHD on the drawing and delivery of ore to an average of 1.2-1.5 times the result is a significant reduction of the yield of oversized ore from 19 to $5 \%$. Counter blasting schemes have quite serious technological potential and can be widely used in similar conditions.

The research was carried out within the framework of the State Assignment No. 075-00581-1900. Topic No. 0405-2019-0005.

\section{References}

1. Yu. V. Volkov, I. V. Sokolov, Underground mining of copper pyrite deposits in the Urals (Ekaterinburg, Ural Branch of the Russian Academy of Sciences, 2006)

2. V. N. Kalmykov, V. Kh. Pergament, S. S. Neugomonov, Vestnik of Nosov Magnitogorsk State Technical University, 1 (2009)

3. I. V. Sokolov, A. A. Smirnov, Yu. G. Antipin, I. V. Nikitin, K. V. Baranovsky, Mining. info-anal. bull., 4 (2013) 
4. V. A. Lapin, Improvement of blasting technology at deep horizons of copper pyrite deposits (Magnitogorsk State Technical University, 2002)

5. Yu. G. Antipin, Mining. info-anal. bull., 3 (2007)

6. B. N. Kutuzov, G. M. Kryukov, B. Ya. Pushkin, Explosion technology, 86-43 (1986)

7. Yu. V. Volkov, V. F Bulatov, I. V. Brezgulevsky, A. N. Grachev, Mining Journ. 6 (1976)

8. A. E. Azarkovich, M. I. Shuifer, G. I. Pokrovsky, Crushing of rock massifs by explosion in the practice of hydraulic engineering (Moscow, Energoatomizdat, 1993)

9. E. I. Boguslavskii, I. A. Volik, News of High. Inst. Mining Journ., 3 (2009) 